Please note that all letters must be typed. Priority will be given to those that are less than $\mathbf{5 0 0}$ words long. All authors must sign the letter, which may be shortened or edited for reasons of space or clarity. All letters received are acknowledged.

\section{Clinical governance}

Sir, - I will support any measure which will improve the quality of care for patients providing the measures stand up to common sense scrutiny and are financed appropriately. That the standards employed are demonstrable takes on particular importance in the wake of the Shipman trial. My concern is that clinical governance will increase the burden of regulation on what is already a highly regulated profession.

Any dentist worth his or her salt will carry out an informal kind of clinical governance to ensure their practice remains efficient and free of complaints. Care must be taken to ensure that the elements of clinical governance provide tangible benefits, not just theoretical ones.

Best practice can be studied and recommendations made by learned bodies but to extend clinical governance down to every particular of running a practice is neither desirable nor useful. I do not think that every aspect of practice activity has to have instructions and protocols like a fast-food chain. I am all for quality but we must not wrap our practices in so much red tape that we can not get in to do the job! Let us all be very careful on how we allow clinical governance to proceed.

\section{B. Spicer}

Middlesburgh

\section{Careers of academic dentists}

Sir, - May I congratulate the authors of the recent paper, 'Views of academic dentists about careers in academic dentistry in the United Kingdom' (Goldacre et al, BDJ, 188: 154-159). The paper clearly highlighted some of the issues faced by dental academics in the UK in the pursuit of their careers. The paper is particularly timely in the wake of the House of Lords Select Committee on Science and Technology (1995) and the Committee of Vice-Chancellors and Principals report $(1997)^{2}$.

One important aspect of the paper is the fact that academic careers in dentistry might be perceived as unattractive. This may be because a 'junior' clinical dental academic has an increasing number of 'hurdles' to negotiate before he or she may be considered for promotion.

For a promotion from junior lecturer to senior lecturer/honorary consultant, for instance, these hurdles often include: obtaining a $\mathrm{PhD}$, achieving a certificate of completion of specialist training in a specialist dental speciality (post-Fellowship), evidence of undergraduate and postgraduate teaching excellence (usually in the form of a postgraduate certificate in teaching and learning), publication of a significant number of quality papers in refereed journals, the supervision of several postgraduate degrees and the acquisition of major research grants. These achievements are normally to be met on the background of a heavy clinical teaching load. The attainment of all the above-mentioned goals is laudable. The length of time and increasing difficulty involved in their attainment, however, may mean that young dentists interested in an academic career are dissuaded from applying for lectureships.

There is, therefore, a need to rationalise these issues in order that the crisis in recruiting dental academics, as described by Sir Rex Richards ${ }^{2}$, is adequately addressed.

\section{A. J. Preston}

Leeds

1 House of Lords Select Committee on Science and Technology. Medical Research and the NHS Reforms. London:1995, HMSO: HL Paper 12.

2 Richards R (Chairman). Clinical Academic Careers: Reports of an Independent Task Force. London: Committee of Vice-Chancellors and Principals, 1997.

Sir, - As a clinical academic in orthodontics, I was interested to read the paper by Goldacre, Lee, Stear, Sidebottom and Richards (BDJ 2000; 188: 154-159) on careers of academic dentists. I have some questions and one observation to make. Has it occurred to the authors to ask how it is that we all seem to have so little time? In orthodontics, there is clear evidence that clinical academics have been leaving in droves over a number of years ${ }^{1,2}$ so is it not more likely that rather than this being due to poorly organised training structures, that there are simply too few of us left or being attracted into academic careers? This begs another question: why did the authors not investigate the different specialities separately? Having recently obtained my $\mathrm{PhD}$, I was looking forward to developing high level research work to strengthen the academic basis of orthodontics in this country but looking round, I have not exactly been trampled in the rush of volunteers. Oh yes, I know what I must do: simply restructure the training (some more) and everyone will come running. If only. This paper, in tinkering naively at the edges, will cause more harm than good: if used as a basis for career development schemes it will mask the plain fact that incentives are lacking resulting in there being too few people who want to do this work. Why else does the sample contain only $7.8 \%$ of orthodontists?

\section{F. Luther}

Leeds

1 Mitchell L. Academic staff who have resigned their University posts. Br J Orthod 1994; 21 : 7578.

2 Howat AP. Full time academic posts in orthodontics. Br J Orthod 1990, 17: 252-255.

Sir, - I read the recent survey by Goldacre et al (BDJ 2000; 188: 154-159) with disappointment and concern for I found their conclusions about the attractiveness of careers in academic dentistry to bear little relationship with other published work, at least as it affects my own specialty of orthodontics. $^{1-2}$

The assumption appears to have been made by the authors that all dental specialties are the same and so the opinions of academic staff can be considered as a whole. I believe this approach to be seriously flawed. It seems to me surprising that no attempt has been made to test for differences between specialties. For example, I would expect to find these existing between restorative dentistry, which is almost exclusively dental school based, and orthodontics and oral surgery which have a large number of consultant posts in district general hospitals to which many academic staff are attracted on completion of their training. ${ }^{1}$

The fact that $45 \%$ of the sample was drawn from the specialties within restorative dentistry, whose training programmes have only recently been formalised, may well explain the author's findings on training, but I find it hard to accept that for orthodontics 'a more structured training programme for junior academics is required'. Not only do all orthodontic trainees undertake supervised research during their specialty training and have done for many years, ${ }^{3}$ but the Specialist Training Committee in Orthodontics has been particularly active in drawing up structured training for academic staff in their subsequent FTTA period. In fact some of us would now regard such training as being in danger of becoming too structured.

But the most inappropriate and simplistic statement is reserved for the final sentence of their paper. Although this appears under 'Discussion' it looks like a conclusion which could have been drafted in the corridors of Whitehall. All we need, it seems, is a little re-organisation of our existing academic training programmes to put matters right. Just how do the authors suggest these improvements in training and 
more especially in the redistribution of academic duties be accomplished without more staff?

It is unfortunate that since Goldacre et al do not distinguish between the opinions of holders of full and part-time academic posts the unattractiveness of the former, at least in orthodontics, does not become apparent. (It would perhaps be just as important to ask those who have left junior academic posts why they did so). Orthodontics currently has 27 full time senior staff (senior lecturer/reader/professor) but only seven full time junior academics in post compared with 18 in 1990. The inability in the recent past to retain full time academic staff lead to the expedient of creating part-time posts which are now variously occupied by specialist practitioners, NHS consultants, and community orthodontists. According to Mitchell there were 26 such posts in $1991^{4}$. While these make a valuable contribution to teaching, they do not usually make a pro-rata contribution to research nor are they occupied by staff who will be in a position to take on full time appointments in due course. Moreover they reduce a head of department's flexibility to cover for staff sickness, study leave etc.

The authors seem content that only $48 \%$ of the junior academic dentists they surveyed planned to pursue wholly or mainly academic careers. Might I suggest that if this applies to orthodontics, as I fear it does, this will merely ensure a continuation of the gradual decline we have seen over the past 20 years?

\section{D. Stephens \\ Bristol}

1 Mitchell L. Academic staff who have resigned their University posts. Br J Orthod 1994; 21: 7578.

2 Howat AP. Full time academic posts in orthodontics. Br J Orthod 1990; 17: 252-255.

3 Hunt NP, Cochrane SM. A guide to postgraduate orthodontic courses in the UK 1997. Br J Orthod 1997; 24. Educational Supplement.

4 Mitchell L. Part-time teachers in orthodontics. BrJ Orthod 1992; 19: 153-155.

\section{Michael Goldacre and Penelope Lee} respond: We would like to thank the correspondents for their interest. Luther and Stephens ask about differences in our study between specialties. Numbers in individual specialties were generally rather small for meaningful comparisons. However, differences between them did not seem great. For example, we summarise responses to our question on job enjoyment in Figure 1, comparing orthodontists with other respondents. Respondents were asked to score their enjoyment of their job on a scale from 0 to 10 , where $0=$ not enjoying it at all and 10 = enjoying it greatly. Because numbers of orthodontists were fairly small, we have aggregated the responses as 0-1, 2-3, 4-6, 7-8, and 9-10. The orthodontists' ratings are perhaps a little more extreme than others a slightly higher percentage at the 'great enjoyment' and at the 'little or no enjoyment' ends of the scale - but similarities are more striking than differences. Differences in responses to other questions, too, seemed unremarkable.

We also compared respondents in restorative dentistry with others. Their responses were also similar.

Our survey had two main components. First, we asked specific, structured questions as reported in our paper. Second, we asked respondents to give us any comments they wanted to make about incentives,

disincentives and any other aspects of a career in academic dentistry. Out of the 377 respondents, 259 (69\%) commented, some briefly and some extensively, raising a wide range of issues. It is difficult to know how representative the comments are and, although we intend to analyse them and write them up, analysis of spontaneous comment is not straightforward. Some, like your correspondents, were very critical of aspects of academic dentistry as it currently is. Comments which seemed typical of negative views included:

\section{- I could no longer advise junior colleagues to enter an academic career. \\ - Many people will 'opt out' because of excessive demands placed upon them. \\ - I fear for the future of academic dentistry.}

Others made positive comments about academic careers like the following:

- Intellectual challenges and stimulation.

- I have had a marvellous career.

- Constant variety of activity.... friends all over the country and the world.

- Escaping the boredom of clinical dentistry!

- The safety of long-term tenured contract.

Others gave comments which were a mixture of positive and negative points; and many made specific points which underpinned the more general comments they made like those above.

In our paper we summarised the quantitative responses to our closed questions as a matter of record. We did not attempt to use our own judgements on many of them but hoped that they would stimulate thought and debate. For example, we drew out the fact that only ' $48 \%$ of junior doctors planned a wholly or mainly academic career' but did not discuss this further. We certainly did not intend to suggest, by omission of comment, that all was well with academic careers. In the final paragraph of our Discussion, we did comment, reiterating a finding from the Results section, that 'it is disquieting that only $61 \%$ of the senior dental academics agreed that, given the choice again, they would choose an academic dentistry post'. We commented briefly on training, making points criticised by Professor Stephens, because $89 \%$ of the respondents in junior posts signified that they 'agreed' or 'strongly agreed' with the statement that 'training in clinical academic posts should be more tightly structured'. We agree that it would have been good to have responses from people who had been in academic posts but had left.

We are aware that there may be interest in details from our survey which, for reasons of space, we did not cover in our paper. Within the limits of confidentiality in relation to our respondents, we are happy to share details with anyone interested.

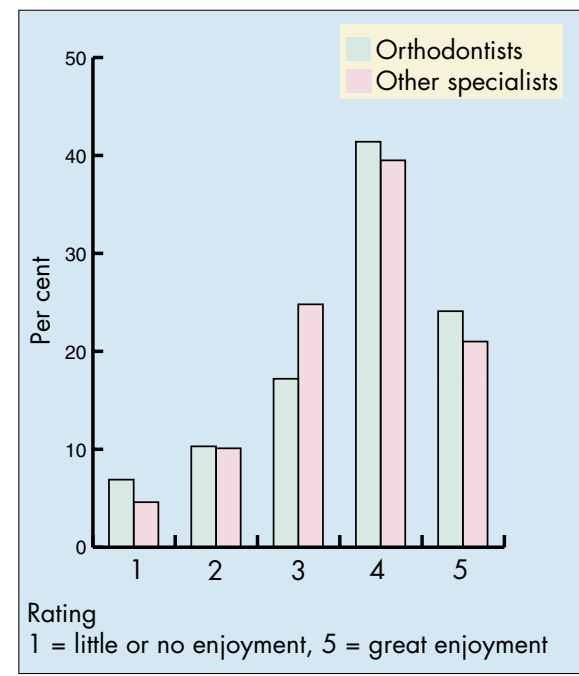

Fig 1 Respondents' rating of enjoyment of job, comparing orthodontists with other specialties

\section{Manchester reunion}

Sir, - There is going to be a silver jubilee in October 2000 for the ex-Manchester Dental School students who qualified in 1975 . We have managed to locate all but four of our colleagues. Could anybody help us contact Bernie Evan Wong, Joan Todd, Ken Woodhead or John Briscoe? We would like to invite them to our silver anniversary reunion.

\section{C. Mackie \\ Unit of Paediatric Dentistry \\ Higher Cambridge Street \\ Manchester M15 6FH}

Please send your letters to: The Editor

British Dental Journal

64 Wimpole Street London, W1M 8AL 